\title{
DESAFIOS DA EDUCAÇÃO NA/DA/PARA A AMAZÔNIA
}

\author{
Rafael Marques Gonçalves \\ Mark Clark Assem de Carvalho
}

O atual cenário da política educacional brasileira discorre à beira da produção de exclusões sociais face às múltiplas formas com as quais o campo, sobretudo o acadêmico, vem sofrendo com violências simbólicas que o reduzem a meras constatações técnicas pautadas por um modelo conservador.

Em diferentes espaços/tempos educadores amazônicos tecem, de formas múltiplas, seja no ensino, na pesquisa ou na extensão, meios e formas de superação que representam não apenas reações a mandos e desmandos de um poder que se pretende total, centralizado, verticalizado e distintamente assimétrico. Noutra margem, geram produções docentes e discentes inspiradas em critérios e possibilidades reais que conotam muito além do que os discursos reducionistas atuais tendem a promover com seus modelos, propostas e padrões, contribuindo para dar voz e visibilidade a outros sujeitos, experiências e práticas.

Frente ao contexto de desmonte, de negação, de reação e enfrentamentos, tensionar e reagir a tal momento é premente e exige multiplicar ações e reflexões, criadas a partir das múltiplas formas de (re)existir cotidianas, diante de condições adversas, sobretudo na região Amazônica. Produzir e fazer circular ações e reflexões críticas e propositivas é necessário e urgente. Neste sentido, a organização de uma sessão temática na Teias, intitulada Desafios da educação na/da Amazônia, é um imperativo para o atual momento em que vivemos no campo científico.

A proposta do dossiê que Teias acolhe visa, então, publicizar ações e reflexões que busquem romper com a hierarquização presente nas relações de poder/saber na sociedade e na educação, levantando questões e buscando alternativas que tragam argumentos para fomentar o debate acadêmico, no qual a preocupação fundamente-se no resistir e (re)existir, em meio a possibilidades, interesses e realidades específicas no/do cotidiano amazônico em suas realidades plurais; no/do cotidiano escolar afeto ao modelo padrão de escola, nas escolas ribeirinhas, rurais em classes multisseriadas com seus sujeitos ímpares, coletivos, regionais e nacionais; nas produções acerca do trabalho docente, de políticas e currículo, de acesso e permanência na educação superior, resultantes de pesquisas educacionais - um campo vasto e em fase de consolidação, desenvolvidas no/do contexto da região Amazônica.

Abrimos a edição com o texto $A$ ameaça "fantasma" da privatizą̧ãa à educaşão básica pública na Amarônia paraense, de Fabrício Aarão Freire Carvalho e Andréa Barbosa Gouveia que, por meio de pesquisa bibliográfica e documental, objetivaram analisar o papel do Estado, a partir da lógica de financiamento proposta pelas novas regulamentações voltadas para a educação básica e seu efeito indutor no processo de mercantilização / privatização da educação pública paraense, no período de 2013 a 2018. Segundo os autores, a análise dos dados revelou tendências de encolhimento do setor público e de avanços do setor privado na oferta da educação básica e no acesso ao fundo público.

No texto Dilemas na implantaşão da educação superior pública em uma IFES na Amazônia, Francisca Márcia Lima de Sousa e Anselmo Alencar Colares e apontam que os desafios educacionais para a efetivação da educação superior são diversificados e exigem esforço coletivo para serem compreendidos. O estudo trata de alguns dilemas que estiveram presentes no processo de implantação do curso de pedagogia em Santarém, cidade localizada no interior da Amazônia 
brasileira, no estado do Pará (PA). O artigo traz uma abordagem histórica das primeiras ações da Universidade Federal do Pará (UFPA), durante a década de 1970, fora da capital. Contextualiza as ações extensionistas e de ensino daquela Instituição Federal de Ensino Superior (IFES) relativas à formação de professores, como um dos mais instigantes desafios na/da região de atuação da UFPA.

Dando continuidade à sessão temática apresentamos o texto $O$ processo de apropriação dos resultados das avaliações externas e do IDEB em escola básica amazônida, de Dinair Leal da Hora e Luziane Said Cometti Lélis, que identifica as implicações das políticas de regulação e avaliação no contexto escolar, analisando o modo como a equipe gestora e os professores de uma escola pública da região Amazônica de Belém/PA se apropriam dos resultados do Índice de Desenvolvimento da Educação Básica (IDEB). A investigação indica que a lógica da política de avaliação nacional reforça a gestão gerencial na escola; demonstra a ausência de discussão sobre as implicações das políticas de regulação e avaliação na escola, o que resulta na aceitação natural da cultura de resultados; e afirma que o IDEB traduz um conceito de qualidade como valor instrumental, quantificável, passível de manipulação, que não representa a realidade concreta do trabalho pedagógico.

No texto intitulado A universidade em regiões amarônicas: pesquisa, ensino e mudança social, Lúcio José Dutra Lord aponta que a universidade tem seu papel discutido na atualidade e que demandas diversas the são dirigidas, gerando desafios para sua consolidação como ator social. No caso da região amazônica, os desafios são envoltos por dinâmicas sociais pautadas pela desigualdade, por históricos de silenciamento e discursos legitimadores do exercício do poder. O artigo discute esses temas a partir da investigação sobre o papel que a Universidade do Estado do Mato Grosso desenvolveu entre 2006 e 2019 na região da Amazônia mato-grossense, por meio de programas de pesquisa e projetos de ensino engajados com a realidade de grupos menos favorecidos. O estudo é de base sociológica e dialoga com perspectivas da análise do discurso e da educação. Como resultado, conclui que o papel e atuação da universidade depende de condições internas e externas, exigindo análise de conjuntura.

$\mathrm{Na}$ sequência, o texto Políticas educacionais na Amarônia: a questão "indígena" no ensino superior de Lucas de Vasconcelos Soares, Maria Lília Imbiriba Sousa Colares e Maria Antonia Vidal Ferreira busca analisar as políticas de acesso e permanência de estudantes indígenas no ensino superior na região amazônica do Brasil, contrapondo tal perspectiva aos procedimentos históricos adotados por órgãos governamentais em torno da efetividade desses princípios da educação, sendo possível verificar que houve significativos avanços nas políticas educacionais em prol da inserção indígena no ensino superior, bem como estas contribuíram para a ampliação do direito à diversidade entre os povos, refletida em legislações posteriores, como a Lei n. 11.645/2008.

O próximo texto intitula-se A reconfiguração da política de assistência estudantil na Universidade Federal do Acre, de Adão Rogério Xavier Silva, Mark Clark Assen de Carvalho e Rafael Marques Gonçalves. Os autores analisam a reconfiguração da Política de Assistência Estudantil (PAE) na Universidade Federal do Acre (UFAC), no contexto de execução do Programa Nacional de Assistência Estudantil (PNAES), tendo como marco de referência o ano de 2013. A partir das análises empreendidas, conclui-se que dois foram os elementos externos que influenciaram a reconfiguração da Política de Assistência Estudantil na UFAC, a saber: o financiamento das Instituições Federais de Ensino Superior (IFES) e as políticas de expansão da oferta do ensino superior nas universidades públicas federais. No que refere ao elemento interno, considerado como movimento inicial do contexto da prática, tem-se a criação de um órgão executivo específico para gestão / execução das Políticas de Assistência Estudantil — a Pró-Reitoria de Assuntos Estudantis (PROAES), que passará a gerir o conjunto das ações voltadas à materialização da política na UFAC. 
O texto Identidade do profissional da educação especial: construção na escola indígena, escrito por Selma Maria Cunha Portela e Roseli Bernardo Silva dos Santos, analisa o processo de construção da identidade profissional do professor da Sala de Recursos Multifuncional que atua no contexto da escola indígena em Roraima. Segundo as autoras, a pesquisa foi realizada em parceria com um grupo de professores e chefes de divisões da Secretaria de Estado de Educação de Roraima (SEED/RR) e compreendeu pesquisa bibliográfica, entrevistas e análise documental. Observa-se que a identidade do profissional da educação especial que atua na escola indígena é constituída de elementos advindos do contexto pessoal, coletivo e da experiência educativa. Recomenda-se, entretanto, considerar a cultura de cada docente indígena.

O texto Experiências de/ com uma "pessoa T" indígena entre-gêneros do/ no cotidiano tocantinense, de autoria de José Damião Trindade Rocha, Marcos Irondes Coelho e Alexandre Araripe Fernandes discute o fato de que ser anunciada como travesti no contexto do dia a dia indica vigilância e punição para qualquer jovem. Em se tratando de uma jovem indígena entre-gêneros, as marcações de preconceito interseccionadas de etnia, gênero, sexualidade, travestilidade, identidade e cultura agem como governamentalidade de seu corpo e de seu ser/existir. Assim, os autores apontam que tensionar esses conceitos e (de)marcá-los na / com narrativas da experiência de "pessoas T" é um desafio para estas pessoas, para a comunidade tradicional indígena e para nós da pesquisa / pesquisadores(as) "implicados" com / na educação.

O texto Contos e encantos infantis ribeirinhosamazônidos no cotidiano escolar, de Edilma de Souza e Maritza Maciel Castrillon Maldonado, assume o compromisso de narrar as singularidades de crianças que fogem de interpretações e itinerários prefixados, a partir de encontros em que as pesquisadoras se detiveram nas operações astuciosas e clandestinas por elas realizadas, pouco observadas no mundo tomado pelo capitalismo. Na esteira da filosofia da diferença, produziram diferenciações aos modos de pesquisar com crianças e de pesquisar as infâncias. As autoras produziram um trajeto investigativo por intermédio da cartografia deleuziana, na busca de vivências e de narrativas infantis. Nessa investidura, às margens de um rio em meio à floresta amazônica, encontraram narrativas de experiências singulares que subverteram a lógica de sentido de um lugar - a escola - para as crianças e para as infâncias.

No texto As filhas negras da mãe Amazônia em um fazẹ científico, Celenita Gualberto Pereira Bernieri, Maria das Dores do Rosário Almeida e Elivaldo Serrão Custódio apresentam a visão de duas mulheres negras quilombolas, sendo uma do estado do Amapá e a outra do estado do Tocantins — mulheres amazônidas, lajense e macacoariense — ativistas, ambas, há alguns anos, nos movimentos de mulheres negras e quilombolas, sejam historicamente cultural, ou ideologicamente político. O estudo se materializa apresentando uma organização de ideias a partir da fundamentação teórica bibliográfica, que apoia a abordagem qualitativa de fatos históricos e sociológicos. Os resultados apontam que essas mulheres negras amazônidas têm grande potencial na produção de conhecimento científico e cultural.

No texto Aprendendo com a Amarônia, Leonardo Ferreira Peixoto apresenta uma narrativa (auto)biográfica de formação em contexto amazônico, relativizando as perspectivas Norte-Sul, no contexto brasileiro, a partir das epistemologias do Sul de Boaventura de Sousa Santos. Segundo o autor, o uso do gerúndio do verbo aprender no título é proposital, uma vez que marca a trajetória de um professor que se reconhece em estado de constante (trans)formação. O texto narra inicialmente as mudanças geográficas e as aprendizagens que decorrem desta mudança, passando para transformações políticasepistemológicas nas aprendizagens com os indígenas da região, concluindo com reflexões sobre aprender a ser parente.

Com autoria de Leila Maria Camargo e Alípio Márcio Casali, o texto Fronteiras da República em Roraima: conflitos e desafios curriculares, trata de fronteiras da República no extremo Norte da 
Amazônia: atravessamentos econômicos, políticos e culturais, nacionais e internacionais no estado de Roraima, e sua incidência sobre a escola como desafios curriculares. Utilizando a metodologia relacional de Michael Apple, circunscreve uma introdução à análise crítica curricular das escolas e do currículo nessa região de múltiplas fronteiras.

Jéssica Rochelly da Silva Ramos e Katia Silva Cunha, no texto A educação do campo como política curricular nas "amazônias": territórios, insurgências e re(existências) discutem a educação do campo como política curricular nas "amazônias", analisando-a não somente como território que se encerra na geografia do país, mas como campo complexo, híbrido, conflituoso, com demandas e disputas em jogo. As autoras objetivam compreender as apostas e investimentos que os docentes fazem nas traduções e produção contextual das políticas de educação do campo em tempos de centralização curricular. Os resultados apontam que os discursos de qualidade fundamentam uma base universalizante - a Base Nacional Comum Curricular (BNCC) —, que intenta sobre a demarcação de limites para a manifestação das diferenças nos currículos das escolas do campo.

Alexsander Luiz Braga Santa Brigida e Evandro de Morais Ramos, no texto Banzeiros do rio Negro e a escola ribeirinba: as aulas de educação física no contexto da binterlândia amarônica, tratam dos primeiros achados de uma pesquisa desenvolvida em nível de mestrado, que busca compreender como as práticas socioculturais das comunidades tradicionais ribeirinhas estão inseridas nos conteúdos programáticos do componente curricular educação física. A partir desses achados na pesquisa de campo, consideram que as práticas socioculturais ribeirinhas estão presentes no conteúdo das aulas de educação física, seja direta ou indiretamente.

Por último, o texto Práticas docentes no ambiente prisional: entre a cela e a sala de aula, de Kely Rejane Souza Anjos Carvalho, Jocyléia Santana Santos e Daniela Patrícia Ado Maldonado, busca conhecer a percepção de professoras e alunas quanto à realidade educacional em que estão inseridas, na Unidade Prisional Feminina (UPF) de Pedro Afonso (Tocantins), com o objetivo de compreender como as docentes exercem sua prática pedagógica e como ocorre o processo de ensino e aprendizagem na referida instituição, locus desse estudo. Por intermédio da sistematização, análise e entrelaçamento de dados, descortinaram resultados que evidenciam distanciamento entre a legislação e o cotidiano do sistema penitenciário, marcado pela falta de materiais didáticos apropriados; pela condição de salas multisseriadas; e pela inexistência de capacitação específica às professoras entrevistadas. Todos esses fatores determinantes que configuram verdadeiros desafios à prática docente no cárcere.

\section{Informações dos autores}

Rafael Marques Gonçalves

Universidade Federal do Acre (UFAC)

E-mail: rafamg02@gmail.com

ORCID: https://orcid.org/0000-0002-9038-1542

Link Lattes: http://lattes.cnpq.br/0460662499829326

Mark Clark Assem de Carvalho

Universidade Federal do Acre (UFAC). Bolsista de Pós-Doutorado CAPES/PROCAD-Amazônia

E-mail:markassen@yahoo.com.br

ORCID: https://orcid.org/0000-0003-3638-9719

Link Lattes: http://lattes.cnpq.br/0736995836464424 